\title{
Effect of In-Situ TiB 2 Particle Addition on the Mechanical Properties of AA 2219 Al Alloy Composite
}

\author{
N.R. Rajasekaran, V. Sampath \\ Department of Metallurgical and Materials Engineering \\ Indian Institute of Technology Madras Chennai - 600036 \\ E-mail: nr_raju2000@ahoo.com,vsampath@iitm.ac.in
}

\begin{abstract}
Aluminium alloy AA2219 was reinforced with $\mathrm{TiB}_{2}$ particles introduced in-situ by the saltmetal reaction technique. The microstructural examinations of the composites clearly reveal the formation of $\mathrm{TiB}_{2}$ particles with a hexagonal morphology. The addition of $\mathrm{TiB}_{2}$ particles results in increased mechanical properties, such as $0.2 \% Y S$, UTS and hardness. The improvement in mechanical properties is correlated to the microstructure.
\end{abstract}

Key words: AA 2219 Al alloy; in-situ composite; salt-metal technique.

\section{INTRODUCTION}

Age-hardenable $\mathrm{Al}$ alloys are highly suitable for a wide variety of engineering applications as they are amenable for considerable improvement in their hardness as well as strength by appropriate control of thermal and mechanical treatment [1]. Aluminium alloy AA 2219 in particular, is used more predominantly in aerospace and defense applications since it possesses a good combination of properties: high strength, good weldability, high strength-toweight ratio, and high stiffness-to-weight ratio [2, 3]. It has attractive low temperature properties as well and is therefore used in the construction of liquid cryogenic rocket fuel tanks. [4]

Copious work has been carried out by researchers around the world on metal matrix composites based on aluminium [5-8]. In preparing the metal matrix composites based on $\mathrm{Al}$, the addition of the reinforcement is generally made to the matrix through ex-situ techniques, such as stir casting, alloying, etc. Some of the major problems associated with the ex-situ techniques are non-uniform distribution of particles within the matrix and poor wettability of the particles by the matrix. On the other hand the particles are distributed more uniformly 
within the matrix in the case of the in-situ composites. Shanmugasundaram et al [9] studied the property improvement of AA 2219 alloy brought about by cryorolling. But the effect of in-situ addition of $\mathrm{TiB}_{2}$ particles to the AA 2219 alloy matrix has not been studied so far. An attempt has therefore been made in this work to study the effect of in-situ introduction of $\mathrm{TiB}_{2}$ on the property improvement of this alloy.

The primary objective of the present work is to study the microstructural features of the particles, such as their size, shape and distribution, and their effect on the mechanical properties of the alloy matrix.

\section{EXPERIMENTAL PROCEDURE}

\subsection{Composite Preparation}

Metal matrix composites with AA $2219 \mathrm{Al}$ alloy as the matrix and different amounts of $\mathrm{TiB}_{2}$ particles (5wt \% and 10wt \%, respectively) as the reinforcement introduced in-situ by the salt-metal reaction technique were prepared. In each of these cases, one $\mathrm{kg}$ of the alloy was weighed into a graphite crucible and melted in a pit-type electric furnace. The molten alloy was then superheated to $800^{\circ} \mathrm{C}$ and a mixture of $\mathrm{K}_{2} \mathrm{TiF}_{6}$ and $\mathrm{KBF}_{4}$ salts was added to the melt to favour the formation of $\mathrm{TiB}_{2}$ particles by an exothermic reaction between the molten alloy and the salts added. Prior to the addition of salt mixture, it was preheated at $200^{\circ} \mathrm{C}$ for $2 \mathrm{~h}$ to get rid of the moisture and volatile impurities.

The addition of the salt mixture was made only after degassing the molten alloy using tablets of hexachloroethane. The salt mixture was slowly added into the melt to facilitate the in-situ reaction. The melt was gently stirred using a graphite rod every $10 \mathrm{~min}$ in a $1 \mathrm{hr}$ reaction time. After the formation of the $\mathrm{TiB}_{2}$ particles, the reaction byproducts, such as the slag containing $\mathrm{KAlF}_{4}$ and $\mathrm{K}_{3} \mathrm{AlF}_{6}$, rise to the top of the molten alloy and were removed by decanting the crucible. The molten alloy/composite was then poured into a preheated $\left(200^{\circ} \mathrm{C}\right)$ mild steel mould of size: $150 \mathrm{~mm}$ x $150 \mathrm{~mm}$ x $12 \mathrm{~mm}$. The schematic setup for composite preparation is shown in Fig. 1.

\subsection{Characterization}

The base alloy and the composites were characterized by X-ray diffraction (XRD) using $\mathrm{Cu}$ $\mathrm{K} \alpha$ radiation, Scanning Electron Microscopy (SEM) and energy dispersive analysis of X-rays (EDAX). The $\mathrm{TiB}_{2}$ particles were extracted from the composite by dissolving the Al matrix using a $20 \% \mathrm{NaOH}$ solution and the extracted particles were characterized by XRD. The density of the composites was determined using Archimedes principle. The hardness of the composites was determined using a Vickers hardness tester at a load of $1 \mathrm{~kg}$. The room temperature tensile tests were carried out using an Instron tensile testing machine (Model: 3367 ) at a strain rate of $10^{-3} \mathrm{~s}^{-1}$. 


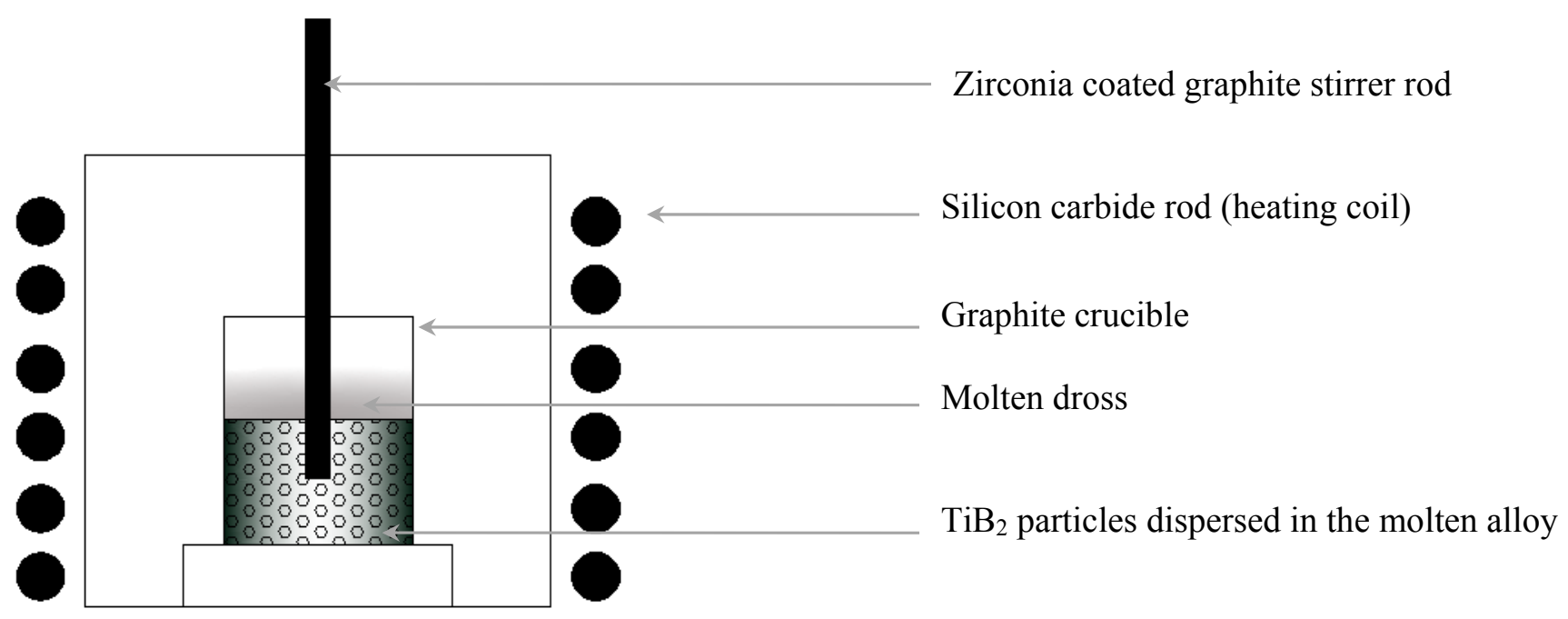

Fig. 1. Schematic setup for composite preparation

\section{RESULTS AND DISCUSSION}

\subsection{XRD}

Fig. 2(a) shows the XRD patterns of composites with peaks corresponding to the Al alloy, $\mathrm{TiB}_{2}$ and $\mathrm{CuAl}_{2}$. It clearly shows the presence of $\mathrm{TiB}_{2}$ peaks composites containing 5 and 10 $w t \%$ of $\mathrm{TiB}_{2}$. The intensity of $\mathrm{TiB}_{2}$ peaks increases with an increase in the amount of $\mathrm{TiB}_{2}$ in the composites. No evidence was found for the formation of the brittle intermetallic $\mathrm{Al}_{3} \mathrm{Ti}$ in the composites. This is attributed to prolong holding of the $\mathrm{Al}_{3} \mathrm{Ti}$ particles leading to its decomposition to give rise to stable $\mathrm{TiB}_{2}$ particles. Fig 2 (b) shows XRD patterns of the extracted $\mathrm{TiB}_{2}$ particles (with peaks indexed) from the composite.

\subsection{Scanning Electron Microscopy}

Fig. $3[(a)-(c)]$ shows the secondary electron images of the as-cast composites. Fig. 3 (a) clearly shows coarse grain boundary network of base alloy in the as-cast condition. Fig. 3 [(b) and (c)] shows the presence of $\mathrm{TiB}_{2}$ particles in the composites with 5 and $10 \mathrm{wt} \%$ of $\mathrm{TiB}_{2}$ showing their uniform distribution in the matrix. By reducing the formation of $\mathrm{Al}_{3} \mathrm{Ti}$ in the composites, the $\mathrm{TiB}_{2}$ particles are distributed more uniformly throughout the matrix. Fig. $3\left[(\mathrm{~d})\right.$ and (e)] shows the presence of $\mathrm{TiB}_{2}$ particles in the composite with $10 \mathrm{wt} \% \mathrm{TiB}_{2}$ at a higher magnification and the hexagonal morphology of it. The EDS analysis also confirms the presence of $\mathrm{TiB}_{2}$ in the composite. The particles were mostly of hexagonal shape with very straight edges and sharp corners. The clear edges of the $\mathrm{TiB}_{2}$ particles can also be seen in Fig. 3 (f).The particle size varies from $0.5 \mu \mathrm{m}$ to $1.5 \mu \mathrm{m}$. The particle size depends on the reaction time. The $\mathrm{TiB}_{2}$ particle has a $\mathrm{C} 32-\mathrm{AlB}_{2}$ type of structure (lattice parameters are $\mathrm{a}=$ $0.3029 \mathrm{~nm}, \quad \mathrm{c}=0.3228 \mathrm{~nm}$, and space group $\mathrm{P} 6 / \mathrm{mmm})$ [11]. The particles were 
homogeneously distributed around the grain boundaries and also can be seen clearly in Fig. 3(e). Agglomerated particles are conspicuous by their absence. Elemental mapping ( $\mathrm{Al}, \mathrm{Cu}$, and $\mathrm{Ti}$ ) was also done to find the distribution of $\mathrm{TiB}_{2}$ particles in the composite. Information relating to the dimensions and morphology of $\mathrm{TiB}_{2}$ can be obtained from Fig. 3(g).

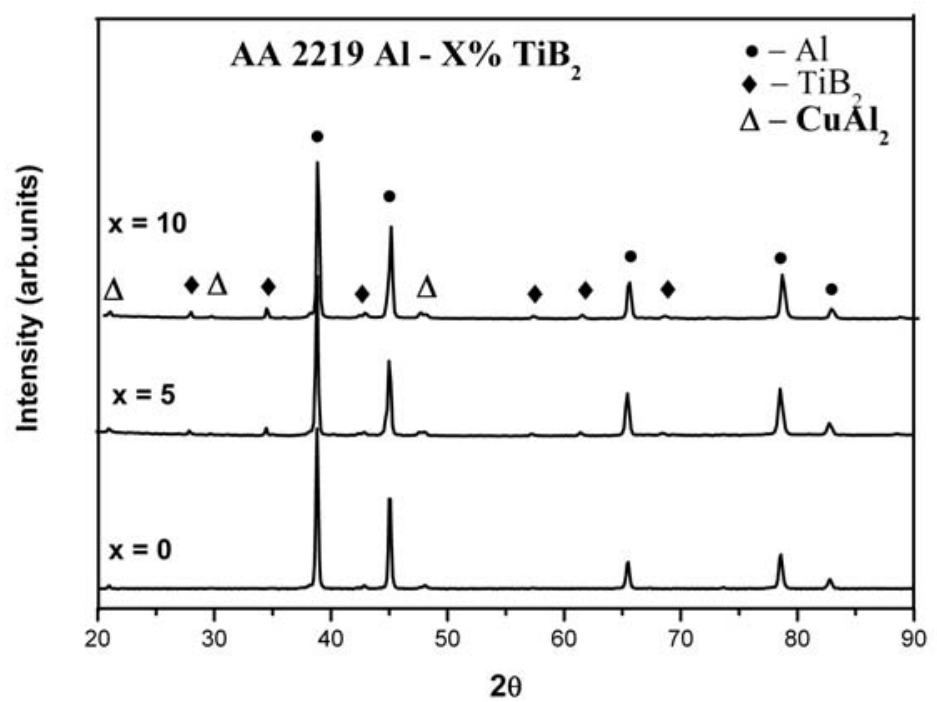

Fig. 2(a). XRD pattern for the base alloy and those for the composites with 5 and $10 \mathrm{wt} \%$ of $\mathrm{TiB}_{2}$.

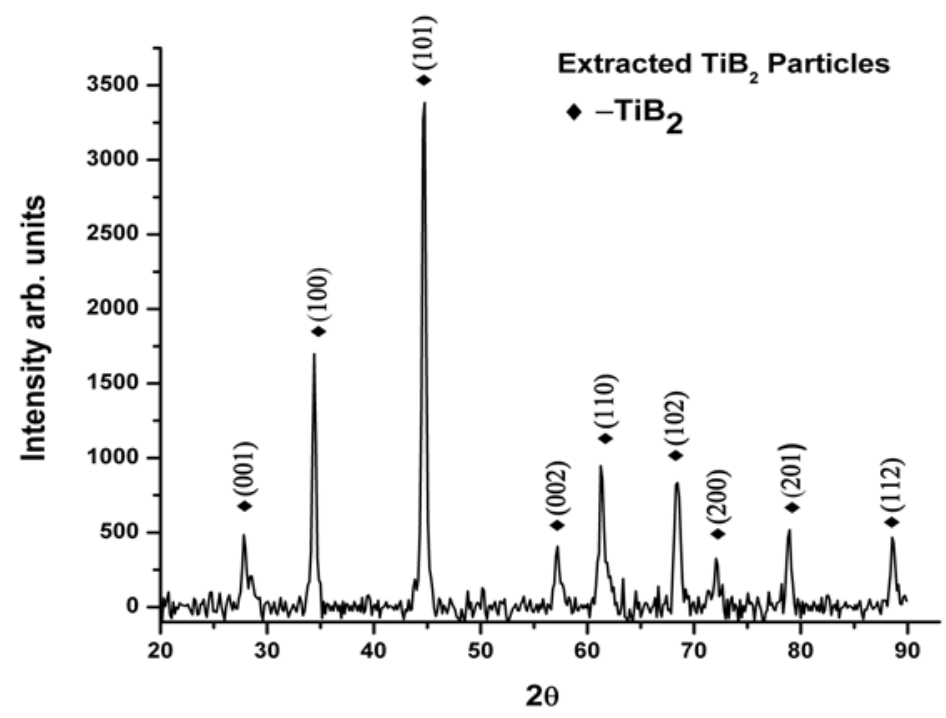

Fig 2 (b) XRD pattern of extracted $\mathrm{TiB}_{2}$ particles (with peaks indexed) for the composite with $10 \mathrm{wt} \%$ of $\mathrm{TiB}_{2}$. 


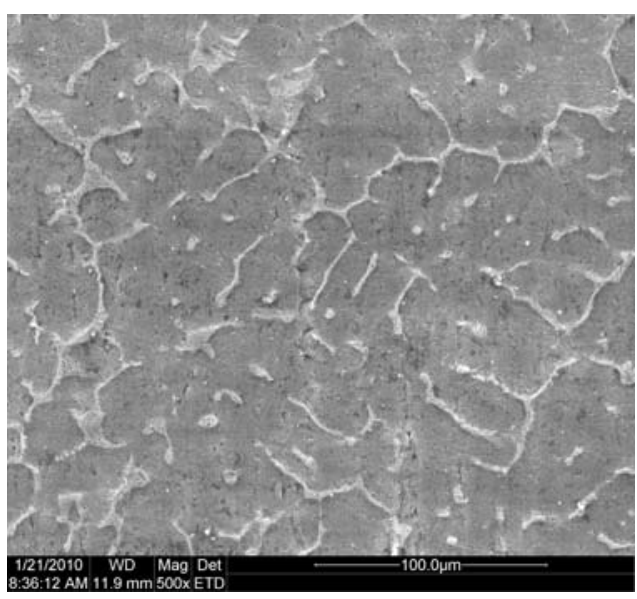

Fig 3(a) Micrograph of as- cast AA 2219 Al alloy

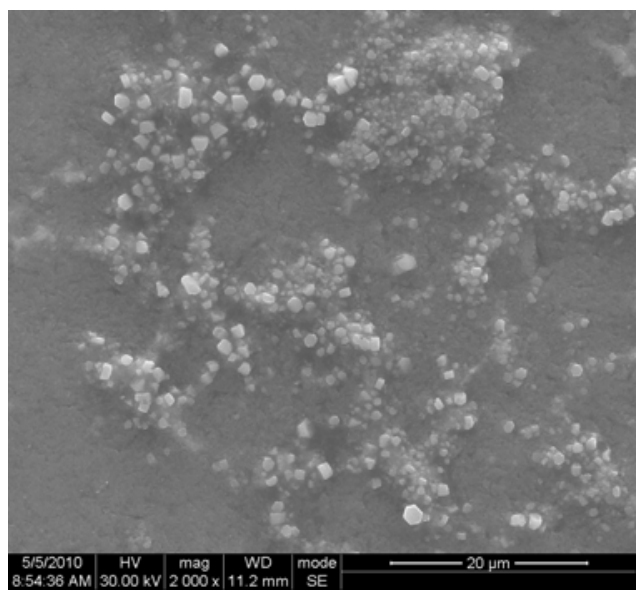

Fig 3 (c) Micrograph of AA2219 Al alloy $-10 \% \mathrm{TiB}_{2} \quad$ Fig 3

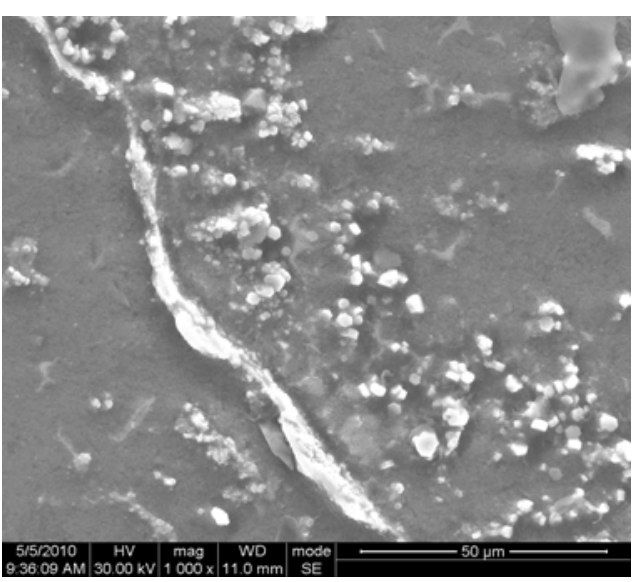

Fig 3 (e) Micrograph showing $\mathrm{TiB}_{2}$ particles forming a network at the grain boundaries in $10 \mathrm{wt} \%$ of $\mathrm{TiB}_{2}$ composite

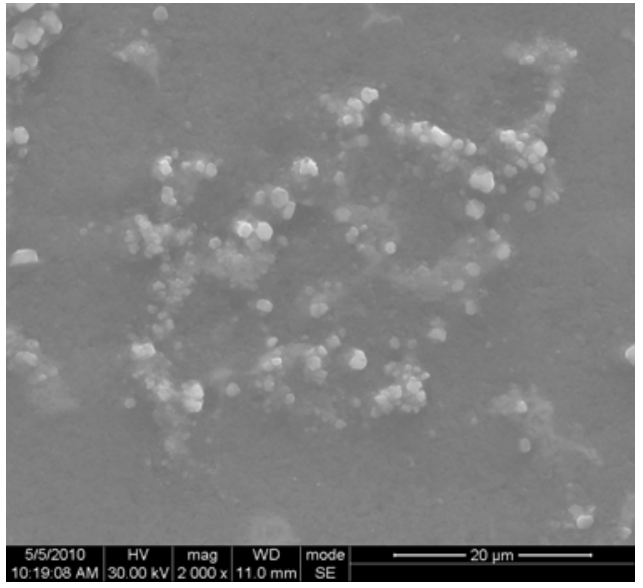

Fig.3 (b) Micrograph of AA2219 Al alloy - 5\% $\mathrm{TiB}_{2}$

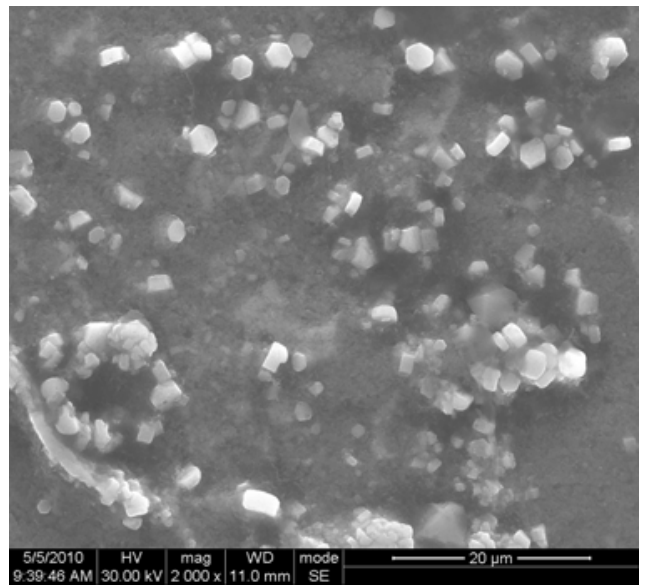

d) Micrograph showing the Distribution of $\mathrm{TiB}_{2}$ particles in $5 \mathrm{wt} \% \mathrm{TiB}_{2}$ composite

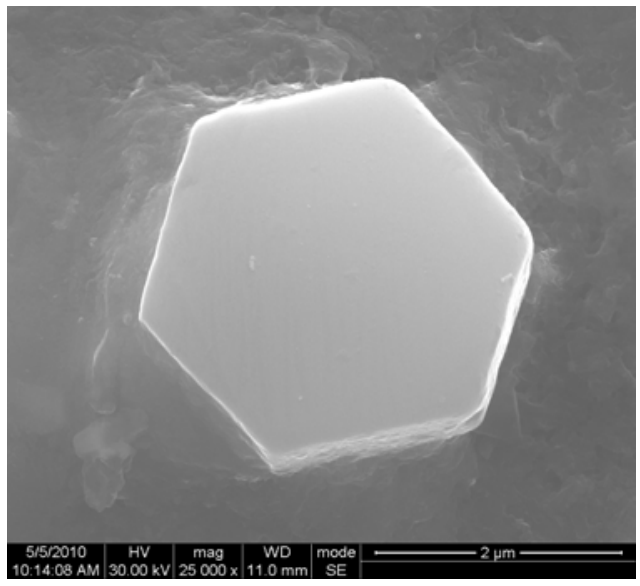

Fig 3 (f) Individual $\mathrm{TiB}_{2}$ particle 

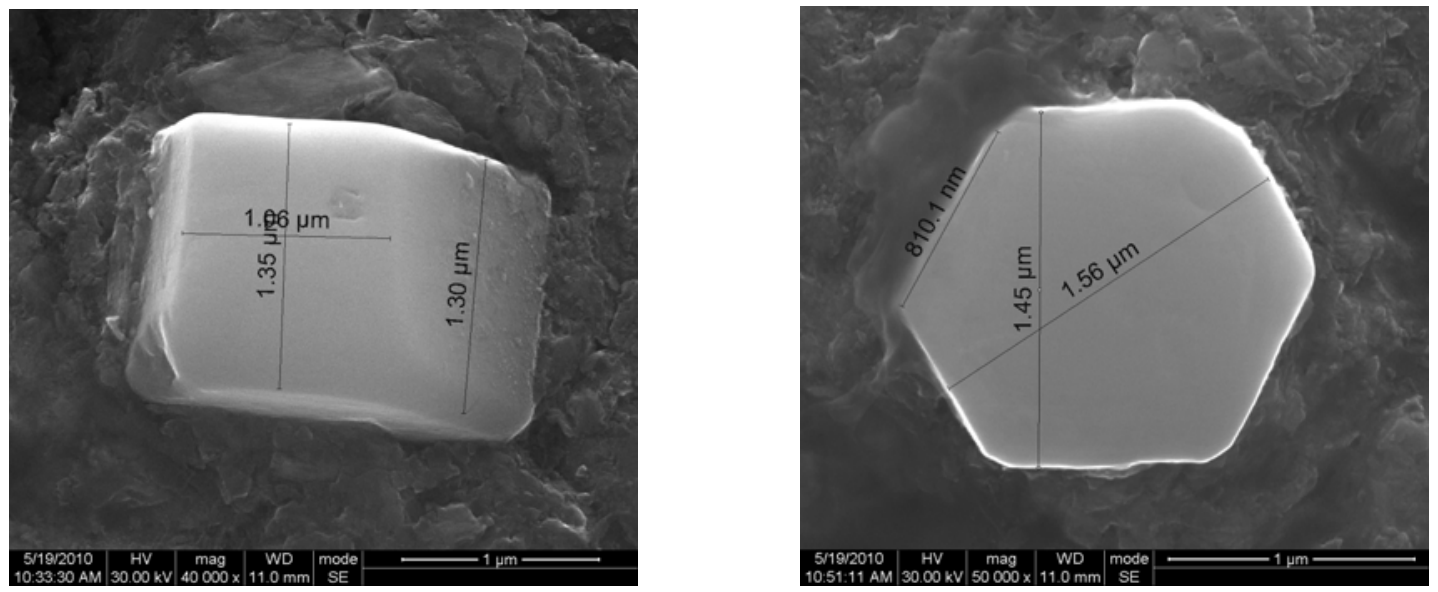

Fig 3 (g) Dimensions of individual $\mathrm{TiB}_{2}$ particle

\subsection{Mechanical Properties}

\begin{tabular}{|l|c|c|c|c|}
\hline Material & $\begin{array}{c}\mathbf{0 . 2 \%} \text { YS } \\
\text { (MPa) }\end{array}$ & $\begin{array}{l}\text { UTS } \\
\text { (MPa) }\end{array}$ & $\begin{array}{l}\text { Hardness } \\
\text { (VHN) }\end{array}$ & Elongation (\%) \\
\hline AA 2219 Al alloy & 144 & 211 & 63 & 11.0 \\
\hline AA 2219 Al alloy - 5\% $\mathrm{TiB}_{2}$ & 165 & 219 & 87 & 7.0 \\
\hline AA 2219 Al alloy - 10\%TiB 2 & 205 & 234 & 96 & 5.8 \\
\hline
\end{tabular}

The yield strength values were measured by $0.2 \%$ offset method. It is clear that the addition of $\mathrm{TiB}_{2}$ particles in-situ to the aluminium alloy matrix increases the mechanical properties of the composite although there is a slight reduction in the ductility. The particle size of the $\mathrm{TiB}_{2}$ in the composite is in the range of $0.5-1.5 \mu \mathrm{m}$ and the particles were well dispersed in the matrix. These are desirable factors for the Orowan strengthening mechanism [10]. The hard in-situ $\mathrm{TiB}_{2}$ particles pin down the dislocation line and favour the formation of Orowan loops (dislocation loops) around the particles. The loops reduce the distance between the particles and thus provide more resistance to further dislocation movement in the composite during deformation. This enhances the strength of the composites. In addition, grain boundary strengthening is also expected because the $\mathrm{TiB}_{2}$ can act as a grain refiner in $\mathrm{Al}$ alloys. An increase in volume fraction of $\mathrm{TiB}_{2}$ particles reduces the grain size of the cast alloy from 115 $\mu \mathrm{m}$ to $\sim 40 \mu \mathrm{m}$ (10 wt \% $\mathrm{TiB}_{2}$ composite). As per the Hall-Petch relationship the yield strength is inversely proportional to the grain size. Hence the yield strength of composite increased due to reduction in grain size. The as-cast alloy shows poor mechanical properties because of its coarse cast structure. The hardness of the in-situ composite is higher than that of the base alloy owing to the reasons put forth earlier.

\subsection{Fractography}

Fig 4 [a and b] show the fractographs of the samples tested in tension. It can be clearly observed that lot of relatively equiaxed dimples and fibrous ligaments are present on the 
surface. It reveals the ductile mode of fracture. Inside the dimples $\mathrm{TiB}_{2}$ particles were very well harboured confirming the good bonding/wettability between the matrix and the in-situ $\mathrm{TiB}_{2}$ particles. The dimples were found to be much shallower due to the presence of $\mathrm{TiB}_{2}$ particles and their size was reduced by increasing the fraction of $\mathrm{TiB}_{2}$ particles. This confirms that the particles are well distributed in, and bonded to, the matrix.

The fractographs clearly show that the composite failed at the interface between the ductile $\mathrm{Al}$ matrix and $\mathrm{TiB}_{2}$ particles and some fibrous ligaments were also observed at the interfaces. This indicates that a small amount of plasticity that the composite undergoes. Since $\mathrm{TiB}_{2}$ particles are anchored at the grain boundaries they will increase the resistance to the crack propagation and therefore it will increase the toughness and strength of composites.
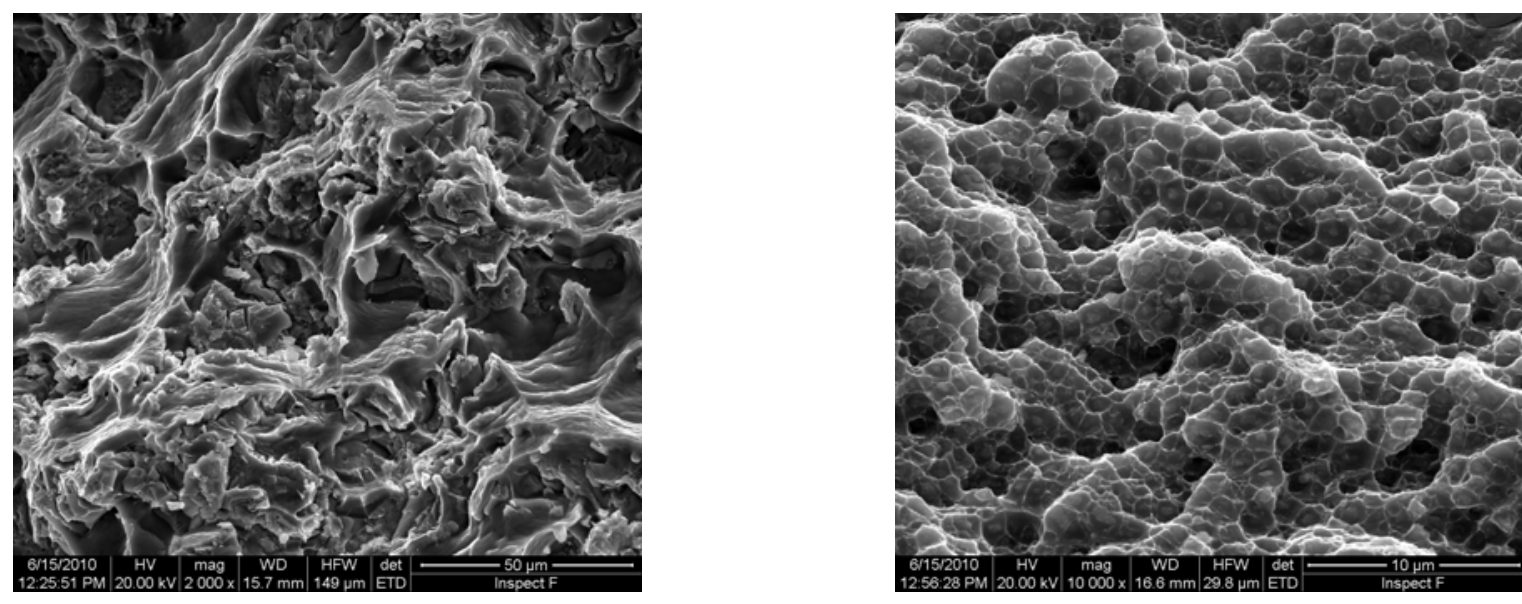

Fig.4 (a) and (b) shows fractographs of as-cast 2219 alloy with $5 \% \mathrm{TiB}_{2}$ and $10 \% \mathrm{TiB}_{2}$ particles.

\section{CONCLUSIONS}

1. In-situ AA2219 Al alloy composites containing different weight fractions of particles of $\mathrm{TiB}_{2}$ phase were synthesized successfully by the salt-metal reaction method and the particles were distributed evenly in the matrix of the composites. By prolonged holding at the solutionizing temperature, the formation of the deleterious phase $\mathrm{Al}_{3} \mathrm{Ti}$, which drastically affects the mechanical properties, was precluded.

2. The particles of the $\mathrm{TiB}_{2}$ phase show a hexagonal morphology with straight and sharp edges.

3. The mechanical properties of the composites were also evaluated and the increased volume fraction of the $\mathrm{TiB}_{2}$ particles contributed to the increased strength of the composites.

\section{REFERENCES}

1. J.R. Davis, ASM Speciality Handbook: Aluminium and Aluminium Alloys 1993. 
2. N. Kamp et al. 2007," Influence of grain structure and slip planarity on fatigue crack growth in low alloying artificially aged 2xxx aluminum alloys" Int. J. Fatigue, 29, pp.869-878.

3. K. Surekha, B.S. Murty, K. Prasad Rao , 2008, “ Microstructural characterization and corrosion behavior of multi pass friction stir processed AA 2219 aluminium alloy" Surface Coatings and Technology, 202, pp. 4057-4068.

4. P. Srinivasa Rao, K.G. Sivadasn, P.K. Balasubramanian, 1996, "Structure- Property correlation on AA 2219 aluminium alloy weldments" Bulletin of Material Science 19, pp. 549-557.

5. Tiejun Ma et al, 2003, "Dry sliding wear behaviour of cast SiC-reinforced Al MMCs" Materials Science and Engineering A, 360, pp.116-125.

6. A. Jha, C. Dometakis, 1997, "The dispersion mechanism of $\mathrm{TiB}_{2}$ ceramic phase in molten aluminium and its alloys" Materials \& Design 18, pp. 297-301.

7. X. Wang et al 1999, " Microstructural analysis of $\mathrm{Al}$ alloys dispersed with $\mathrm{TiB}_{2}$ particulate for MMC applications “ Journal of Microscopy, 196, pp 137-145.

8. I.G. Watson et al. 2005, "Investigation of the clustering behaviour of titanium diboride particles in aluminium" Composites: Part A, 36, pp 1177-1187.

9. T. Shanmugasundaram, B.S. Murty, V. Subramanya Sarma, 2006, “ Development of ultrafine grained high strength Al-Cu alloy by cryorolling" Scripta Materialia 54, pp.2013-2017

10. L. Iain, Principles of Mechanical Metallurgy, Edward Arnold, Ltd., 1981, pp.155

11. Degang Zhao et al, 2005, "In-situ preparation of Al matrix Composites reinforced by $\mathrm{TiB}_{2}$ Particles and sub micron $\mathrm{ZrB}_{2}$ " Journal of Material Science, 40, pp 4365-4368. 